\title{
SMARTPHONES AND SELF-REGULATED LEARNING: OPPORTUNITIES AND CHALLENGES
}

\author{
Kendall Hartley and Lisa D. Bendixen \\ University of Nevada, Las Vegas, Nevada, USA
}

\begin{abstract}
This paper reviews the intersection of self-regulated learning and the smartphone. Self-regulated learning constructs are described with an eye towards the implications for the smartphone-using learner. Research supported practices that inform how the smartphone might be best used are also reviewed.
\end{abstract}

\section{KEYWORDS}

Self-Regulation, Smartphone, Metacognition

\section{INTRODUCTION}

The ubiquity of the smartphone presents numerous opportunities and challenges to educators and learners. Of particular interest is the role of the smartphone in the view of the user as it relates to learning. In any learning environment, the smartphone can serve as a support or a hindrance. The role it plays is dependent upon a number of factors. The choices of the student about how the device is used, or not used, are primary factors.

In practical terms, these choices might include decisions regarding configuration settings such as notification permissions (e.g., should the phone alert me when a friend makes a new post) or multitasking (e.g., should I listen to music while studying). These choices are guided by the user's understanding of his or her own learning and the capacity or motivation to act on these understandings. In other words, self-regulated learning (SRL).

While the introduction of the smartphone into virtually every learning environment is relatively new, the role of SRL in learning environments is not. There is a rich body of literature investigating the role of SRL in a variety of settings (Dent \& Koenka, 2016). Investigations of the direct and indirect impact of smartphones on SRL are emerging. The intersections of these two bodies of literature are such that it is now possible to provide preliminary evidence-based guidance to learners and educators on the efficient use (or non-use) of the smartphone.

This review will draw on SRL research and studies of the use of the smartphone in educational settings to propose a set of evidence-based practices. The practices discussed here will be focused on the students studying behaviors rather than classroom activities. Suggestions for instructors can be found in a review by Flanigan and Kierwa (2018).

\section{CONTEMPORARY SELF-REGULATED LEARNING}

Self-regulated learning research is quite broad and it can be difficult at times to determine the boundaries. Usher and Schunk (2018) provide the following generalization that is useful for this paper:

The process of systematically organizing one's thoughts, feelings, and actions to attain one's goals is now commonly referred to as self-regulation. In this information rich, fast-paced world, individuals are presented with many possible paths of thought and behavior, which can sometimes feel overwhelming. (p. 19). 
SRL researchers typically distinguish between knowledge and regulation of cognition (Schraw \& Dennison, 1994) and this distinction will be used to guide the organization of the paper. Knowledge of cognition includes an individual's toolbox of learning strategies and the awareness of individual strengths and weaknesses. For example, a student may recognize that if they listen to music while reading, they are more likely to become distracted. Regulating cognition refers in part to the propensity of the learner to act upon his or her own knowledge of cognition. In other words, it is not enough for a learner to simply be aware of her own distractibility, they must act upon that knowledge (e.g., turn off the music while reading).

\subsection{Knowledge of Cognition}

In this and the subsequent section, SRL will be described in more detail. Within each description, a connection to the use of the smartphone and potential guiding principles will be proposed.

\subsubsection{Cognitive Skills}

The learners understanding of cognition can take several forms. For example, individuals have a sense of their own working memory capacity. When faced with remembering something like a street address, they will know whether or not they need to write down the address. This is a recognition of the limits of their own cognitive capacity. They also have some understanding of how quickly they can read. When faced with a reading assignment, they will have some sense of how much time they will need to allocate to the task.

The implications of smartphone use for one's knowledge of cognitive skills include the recognition that the phone itself may effectively reduce the student's available cognitive capacity. One study indicated that the mere presence of a smartphone can reduce cognitive capacity (Ward, Duke, Gneezy, \& Bos, 2017).

Conversely, the more skillful learner might view the smartphone as a memory support. For example, an awareness of the limitations of working memory could be combined with a similar awareness of the potential use of the smartphone to augment memory. Skills such as the ability to use task management apps to their full potential would be helpful.

\subsubsection{Learning Strategies}

A student's knowledge of cognition also includes their repertoire of learning strategies. Skillful learners have a broad range of strategies that can be utilized across a variety of learning tasks. Common examples for reading comprehension include the use of self-questioning and note-taking while reading.

Students may or may not recognize the potential value of the phone as a tool to support learning strategies. For example, speech recognition on most phones is now advanced enough to support relatively seamless notetaking. Skillful learners can test these applications and determine how and when they can be used efficiently.

Self-assessment tools also exhibit promise. These apps need to be simple, customizable, and provide useful feedback (Lazarinis, Verykios, \& Panagiotakopoulos, 2017). Like any tool, the usability, setup, and maintenance of the app must be limited to ensure time-on-task is maximized.

\subsubsection{Views of Learning}

The student's beliefs about what knowledge is and how to best acquire that knowledge guide how they engage in educational settings. For example, a student who believes that intelligence is innate or fixed is less likely to see the value in exerting effort towards learning (Haimovitz \& Dweck, 2017). This can be contrasted with a growth mindset where the student understands the value of effortful learning.

Related views of learning concern the individual's self-concept. For some students, it is critical that they be viewed as smart by others. This can have negative consequences for learning when the more skillful action might be to ask a question but the student chooses to remain silent in an effort to maintain smart status.

A recognition of the need for effortful learning might support the view of the phone as a device that can facilitate the requisite effort. Alternatively, a view of the importance of effortful learning can manifest as a recognition that the device can often present a barrier to focused effort. These views are not mutually exclusive given that how the phone is used ultimately determines the impact. 
One promising approach is to confront the learner with the ways in which the phone is currently being used. People tend to underestimate the time spent on the phone engaging in non-productive tasks and overestimate the time spent on productive tasks. A variety of apps are now available that can report on time spent as well as support goals directed at a more productive use of the phone (van Velthoven, Powell, \& Powell, 2018). The information provided can support the learner's reflection on how the use of the phone might be more consistent with their views of learning.

\subsection{Regulation of Cognition}

In contrast to the previous section where the concern is the learner's knowledge, regulation of cognition is concerned with the actions of the learner. While it is necessary to have the requisite understanding of one's thinking, little can be gained if that understanding is not put into action. This section will review a number of examples of regulating cognition and the potential role of the smartphone.

\subsubsection{Goal Setting and Planning}

Successful students are more likely to engage in short and long term goal setting. Goals typically result in some level of planning. These students are more likely to write down goals and build plans to support the goals.

Phones can be used in a variety of ways to support goal setting and goal attainment. Regular reminders can be planted conspicuously on the phone. For example, goals can be placed on a phone's, lock screen or background. The phones can also be set to send goal reminders at regular intervals. Bedesem and Dieker (2014) describe an instructor guided approach that utilizes Twitter and Hootsuite to send automated text messages at regular intervals to students. Similar student guided approaches can be initiated through a variety of calendar and task management apps.

\subsubsection{Information Management}

Efficient students can organize necessary materials and information in a manner that facilitates seamless storage and retrieval. As most parents can attest, this is not an innate skill for young adults.

Today's smartphone has the potential to be a strong ally in the quest to become more organized. Unfortunately, this potential is often lost amongst the vast capabilities of the technology. For the phone to support efficient information management, the learner must utilize a simple and focused strategy for the storage and retrieval of information. This might include the use of one focal information management app or it might be a combination of tools. The important idea is that the learner has crafted a strategy that supports their own information management needs.

Regular use of a cloud-based storage app will figure centrally in the students' approach to information management. While it is tempting to believe that college age students will be adept at using these types of tools, there are indications that their facility with productivity functions is lacking (Maderick, Zhang, Hartley, \& Marchand,2016). It is clear that the phones can be useful in this regard but students will need be guided in the more advanced uses of cloud storage applications.

\subsubsection{Monitoring}

Well-regulated learners regularly engage in monitoring for understanding. For example, while reading they are adept at recognizing when they have lost the train of thought of the author. They recognize this event and retrace their steps accordingly. They also have a good sense of whether or not they understand material sufficiently to perform well on an exam.

The role of the phone in monitoring for understanding is not clear. It could play a role in reminding the learner to consistently engage in appropriate monitoring. However, ill-timed reminders might do more harm than good (see next section). Reminders set for the beginning and ending of a study session might avoid potential harm.

\subsubsection{Attention / Distraction}

Efficient learning is dependent, in part, upon the willingness of the learner to establish a study environment that is free of distraction. This might include the organization of the student's desk to be clear of items that do not support the current task. Finding a quiet and isolated location can also support sustained attention. 
Smartphones present substantial, but not insurmountable obstacles in this regard (Gazzaley \& Rosen, 2016). Software developers have a strong incentive to encourage frequent and extensive engagement with their particular app (Carr, 2011). In support of this, virtually all applications will now request permission to 'notify the user of $X$ '. Notifications would be more aptly termed distractions and are avoided scrupulously by the focused learner.

\section{CONCLUSION}

The challenges to learning presented by the ever-present smartphone are apparent. However, these challenges reflect uses of the technology rather than any deficit inherent in the device. If these devices are to continue to be present in learning environments - there is every indication that they will - it is imperative that the uses be directed toward those that promote rather than hinder learning.

Promoting SRL requires providing students with models of skillful behavior (Schraw, Crippen, \& Hartley, 2006). This can be accomplished by guiding the students towards uses of the phone that are consistent with skillful SRL.

\section{REFERENCES}

Bedesem, P. L., \& Dieker, L. A. (2014). Self-Monitoring With a Twist: Using Cell Phones to CellF-Monitor On-Task Behavior. Journal of Positive Behavior Interventions, 16(4), 246-254. https://doi.org/10.1177/1098300713492857

Carr, N. (2011). The Shallows: What the Internet is Doing to Our Brains. WW Norton \& Company, New York.

Dent, A. L., \& Koenka, A. C. (2016). The Relation Between Self-Regulated Learning and Academic Achievement Across Childhood and Adolescence: A Meta-Analysis. Educational Psychology Review, 28(3), 425-474. https://doi.org/10.1007/s10648-015-9320-8

Flanigan, A. E., \& Kiewra, K. A. (2018). What College Instructors Can Do About Student Cyber-slacking. Educational Psychology Review, 30(2), 585-597. https://doi.org/10.1007/s10648-017-9418-2

Gazzaley, A., \& Rosen, L. D. (2016). The Distracted Mind: Ancient Brains in a High-Tech World. MIT Press, Boston, USA.

Haimovitz, K., \& Dweck, C. S. (2017). The Origins of Children's Growth and Fixed Mindsets: New Research and a New Proposal. Child Development, 88(6), 1849-1859. https://doi.org/10.1111/cdev.12955

Lazarinis, F., Verykios, V. S., \& Panagiotakopoulos, C. (2017). A Mobile Application for User Regulated Self-Assessments. International Association for Development of the Information Society. Retrieved from https://eric.ed.gov/?id=ED579199

Maderick, J. A., Zhang, S., Hartley, K., \& Marchand, G. (2016). Preservice teachers and self-assessing digital competence. Journal of Educational Computing Research, 54(3), 326-351.

Schraw, G., Crippen, K. J., \& Hartley, K. (2006). Promoting self-regulation in science education: Metacognition as part of a broader perspective on learning. Research in Science Education, 36(1-2), 111-139.

Schraw, G., \& Dennison, R. S. (1994). Assessing Metacognitive Awareness. Contemporary Educational Psychology. 19 , (460-475).

Usher, E. L., \& Schunk, D. H. (2018). Social Cognitive Theoretical Perspective of Self-Regulation. In Handbook of Self-Regulation of Learning and Performance. https://doi.org/10.4324/9781315697048

van Velthoven, M. H., Powell, J., \& Powell, G. (2018). Problematic smartphone use: Digital approaches to an emerging public health problem. Digital Health, 4. https://doi.org/10.1177/2055207618759167

Ward, A. F., Duke, K., Gneezy, A., \& Bos, M. W. (2017). Brain Drain: The Mere Presence of One's Own Smartphone Reduces Available Cognitive Capacity. Journal of the Association for Consumer Research, 2(2), $140-154$. https://doi.org/10.1086/691462 